\section{Evaluation of Chirp and Binary Codes based Excitation Pulses for 3D USCT} M. Zapf, B.F. Derouiche, N.V. Ruiter

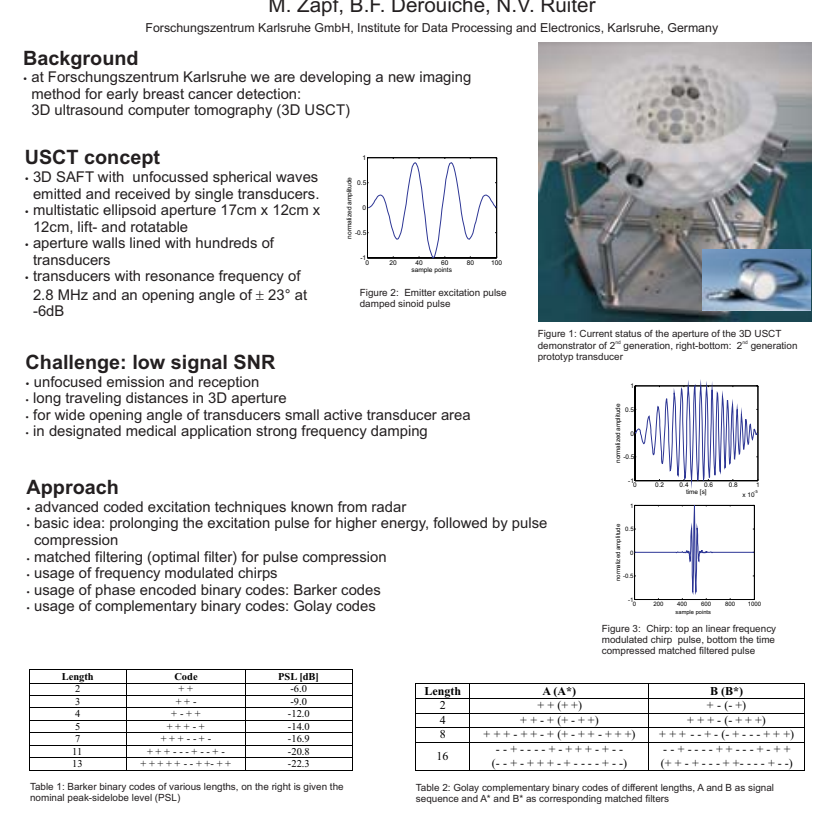

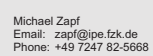

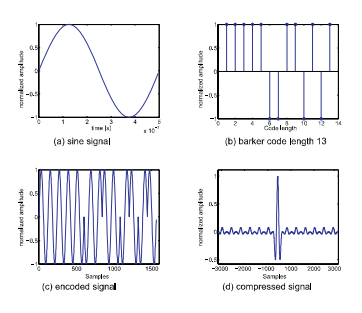

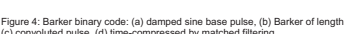

\section{Methods}

Measurement setup

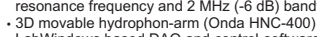

:- LC W Wased G Gage digitization card (20MHHz)

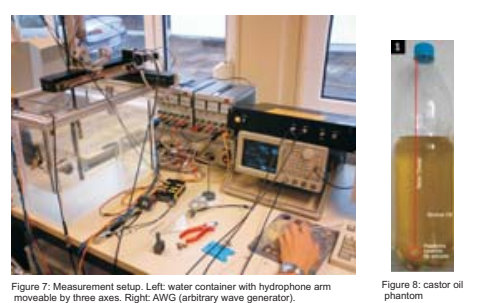

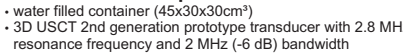

\section{Results}

Evaluation

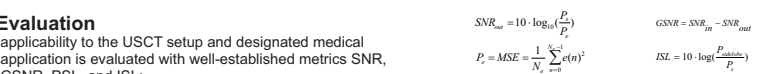

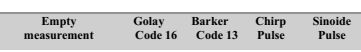

SNR |AB|

GSSR [AB]]

ISTI IDI

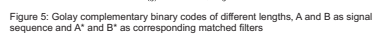

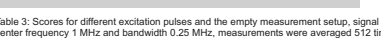

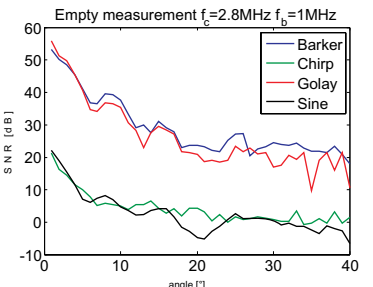

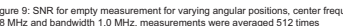

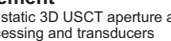

vate signal processing and transducers
surement was done for varving angular

position of the hydrophone
Phantom measurement

- breast tissue mimicking phantom

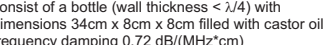

Evaluated pulses

sinoid pulse and linear chirp pulse
Barke for lenth 13 and Golay of length 16, both
convoluted with the sinoide pulse
Discussion

.

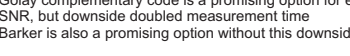

Outlook

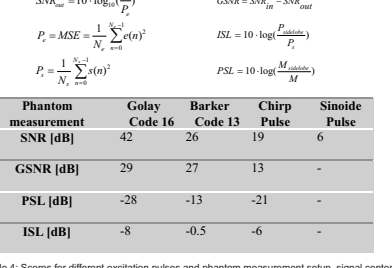

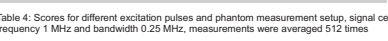

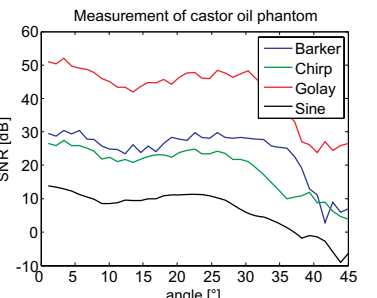

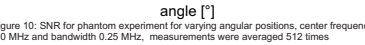

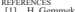

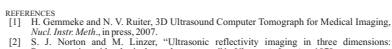

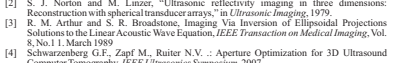

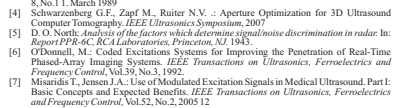

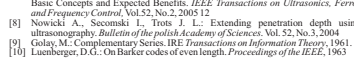

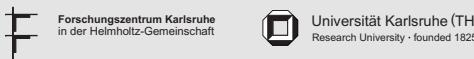

